\title{
HUBUNGAN PERAN ORANG TUA DAN KETERJANGKAUAN TEMPAT \\ PELAYANAN KESEHATAN DALAM PEMBERIAN IMUNISASI DASAR \\ LENGKAP DI WILAYAH KERJA PUSKESMAS DAIK \\ KABUPATEN LINGGA TAHUN 2020
}

\author{
Kartina \\ Program Studi Ilmu Keperawatan STIKes Awal Bros Batam \\ Email : kartinatina214@gmail.com \\ Pembimbing I Mira Agusthia, S.Kep. Mkep \\ Pembimbing II Rachmawaty.M.Noer, S.Kep, M.Kes
}

\begin{abstract}
ABSTRAK
Imunisasi merupakan upaya untuk memberikan kekebalan dalam diri seseorang secara aktif terhadap suatu penyakit. Anak yang tidak mendapatkan imunisasi lengkap maka akan berdampak pada PD3I (Penyakit yang Dapat Dicegah Dengan Imunisasi) dan AKB ( Angka Kematian Bayi). Pemahaman mengenai imunisasi sangat diperlukan orang tua sebagai dasar memenuhi kebutuuhan kesehatan anak. Pemberian imunisasi sebagai upaya pemeliharaan kesehatan anak. Keterjangkauan jarak terhadap fasilitas kesehatan dengan situasi dan kondisi merupakan tantangan yang cukup besar di dalam pemberian imunisasi secara merata di Indonesia. Adapun penelitian ini bertujuan untuk mengetahui peran orang tua dan keterjangkauan tempat pelayanan kesehatan dasar lengkap. Rancangan penelitian adalah Cross Sectional dengan metode pengambilan sampel teknik Purposive Sampling. Sampel dalam penelitian ini terdiri dari 69 pasang orang tua.Hasil penelitian diperoleh 69 responden yaitu bayi yang mendapatkan imunisasi lengkap sebanyak 33 orang $(47,8 \%)$, peran ayah dan ibu mayoritas buruk yaitu 38 orang $(55.1 \%)$ dan 43 orang $(62,3 \%)$. keterjangkauan tempat pelayanan kesehatan mayoritas tempat pelayanan yang terjangkau 38 orang $(55,1 \%)$.Kesimpulan penelitian ini yaitu semua variabel yang diteliti mempunyai hubungan dalam pemberian imunisasi dengan status imunisasi dasar lengkap pada bayi karena $P$ value $<0.05$. Diketahui peran Ayah $p$ value $=0.024$, peran Ibu $p$ value $=0.043$, keterjangkauan tempat pelayanan kesehatan $p$ value $=0.001$. Saran Peneliti Hendaknya mengimunisasikan anaknya tepat waktu, mengingat imunisasi sangat penting untuk kesehatan anaknya masa depan.
\end{abstract}

$\begin{array}{ll}\text { Kata Kunci } & \text { : Peran Orang Tua, Keterjangkauan Tempat Pelayanana Kesehatan, } \\ \text { dan Kelengkapan Status Imunisasi Dasar }\end{array}$

Daftar Bacaan ： $25(2008-2019)$ 


\title{
NURSING MAJOR
}

AWAL BROS INSTITUTE OF HEALTH SCIENCES BATAM

\author{
Mini Thesis, March 2020 \\ Kartina
}

Relations Role People Old And Affordability The Ministry of

Health In granting Immunization Basic Complete In Region Work Puskesmas Daik

Lingga Regency in 2020

$x i+52$ pages +10 tables +2 scheme +6 attachments

\begin{abstract}
ABSTRACK
Imumunization is an attempt to provide immunity in themselves a person active against a disease. Kids who do not get immunized complete then it will have an impact on PD3I (diseases that can be preventes with immunization) and IMR (Figures Death Infant). An understanding of immunization is needed by parents as a basis for fulfilling children's health needs. Provision of immunization as an effort to maintain children's health. The affordability of the network of health facilities and situations and conditions is a significant challenge in providing immunization equally in Indonesia. This study aims to determine the role of parents and the affordability of health services in the delivery of immunizations with complete basic. The study design was was Cross Sectional with a purposive sampling technique sampling method. The sample in this study consisted of 69 pairs of parent The result were obtained 69 responden that babies who receive immunizations complete as many as 33 people $(47.8 \%)$, the role of father and mother majority of the poor are 38 people $(55.1 \%)$ and $43(62,3 \%)$. Affordability point of care health majority where services are affordable $38(55.1 \%)$. The conclusion of this study is that all variables studied have a relationship in providing immunization with complete basic immunization status in infants because $\mathrm{P}$ value $<0.05$. It is known that the role of Father $p$ value $=0.024$, the role of Mother $p$ value $=0.043$, the affordability of health service places $p$ value $=0.001$. researcher Suggestion it should be to immunize their children on time, considering that immunization is very important for the future health of their children.
\end{abstract}

Keywords : Role of Parents, Affordability of Health Care Services, and Completeness of Basic Immunization Status

Reading list $\quad: \quad 25(2008-2019)$ 


\section{PENDAHULUAN}

Imunisasi merupakan upaya untuk observasi dan bantuan tenaga kesehatan memberikan kekebalan dalam diri seseorang Pustu Polindes dan Poskesdes wilayah kerja secara aktif terhadap suatu penyakit. puskesmas Daik sebanyak 226 anak masih Apabila disuatu saat nanti seseorang terkena ada 78 anak yang tidak melakukan penyakit maka tidak akan mengalami sakit imunisasi, saat tenaga kesehatan melakukan atau hanya terjadi sakit ringan. Bayi lebih posyandu imunisasi dan kunjungan keluarga rentan terkena penyakit dan kondisi yang sehat di wilayah kerja Puskesmas Daik, ini tidak sehat dibandingkan dengan orang dewasa. Kekebalan tubuh yang belum terbentuk dengan baik dapat mengakibatkan bayi dengan mudah tertular oleh penyakit (Isnayni,2016). Penelitian epidemiologi di Indonesia dan Negara-negara lain ketika ada wabah campak, difteri atau polio, anak yang sudah mendapatkan imunisasi dasar lengkap sangat jarang yang tertular, bila tertular hanya ringan dan tidak berbahaya. Tetapi anak yang tidak mendapatkan imunisasi, ketika ada wabah lebih banyak yang sakit berat, meninggal atau cacat (Soedjatmiko, 209). Penelitian oleh Dita (2015) memaparkan hasil bahwa kelengkapan imunisasi dasar pada balita dipengaruhi oleh faktor pengetahuan, dukungan keluarga, keprcayaan dan peran petugas. Tinggi rendahnya cakupan imunisasi dapat dipengaruhi oleh berbagai faktor antara lain lokasi imunisasi, kehadiran petugas, usia orang tua, tingkat pendidikan dan pendapatan dan dukungan keluarga dan masyarakat (Adzaniyah,2014). Pada studi pendahuluan yang dilakukan penulis melalui dikarenakan orang tua yang menolak anaknya dilakukan imunisasi. Alasan orang tua yang menolak anaknya dilakukan imunisasi karena kepercayaan mereka tentang kandungan vaksin imunisasi tidak halal dan dapat menyebabkan anaknya demam dan sakit. Dalam hal ini dapat disimpulkan bahwa kurang nya pengetahuan orang tua tentang penting nya imunisasi bagi anak agar dapat mencegah timbulnya penyakit. Ibu juga kurang mendapat dukungan dari suami karena suami juga tidak memahami dengan baik tentang penting nya anak mendapatkan imunisasi dasar lengkap. Jadi, dapat disimpulkan bahwa peran orang tua sangat penting dalam menjaga kesehatan anak dan keluarganya.

$$
\text { Keterjangkauan jarak terhadap }
$$
fasilitas kesehatan dengan situasi dan kondisi geografis yang sangat beragam merupakan tantangan yang cukup besar di dalam pemberian imunisasi secara merata di Indonesia. Tanpa akses yang mudah dan murah untuk dijangkau tentunya akan menyulitkan masyarakat terutama masyarakat yang berpenghasilan rendah 
untuk memperoleh layanan imunisasi kepada anak-anak mereka. Tidak tercapainya target cakupan imunisasi lengkap antara lain dipengaruhi oleh bagaimana masyarakat dapat mencapai akses ke fasilitas kesehatan. Bagi mereka yang tinggal di daerah perkotaan yang memiliki fasilitas kesehatan lengkap baik rumah sakit maupun klinik dapat dengan mudah untuk melakukan imunisasi, akan tetapi bagi yang tinggal di perdesaan dengan fasilitas yang terbatas menyebabkan tidak semua bayi memperoleh layanan imunisasi. Tujuan penelitian ini yaitu Untuk mengetahui Hubungan Peran Orang Tua Dan Keterjangkauan Tempat Pelayanan Kesehatan Dalam Pemberian Imunisasi Dasar Lengkap Di Wilayah Kerja Puskesmas Daik Lingga Tahun 2020.

\section{METODE PENELITIAN}

Penelitian yang dilakukan dengan menggunakan rancangan studi potong lintang (cross Sectional). Sampel yang digunakan peneliti yaitu teknik Purposive Sampling dengan jumlah sampel sebanyak 69 pasang orang tua di wilayah kerja Puskesmas Daik. Pengumpulan data menggunakan lembar kuisioner dan observasi lembar check klis. Data yang terkumpul dianalisis menggunakan computer dengan SPSS data univariat maupun data bivariat.
HASIL DAN PEMBAHASAN

\section{HASIL ANALISIS UNIVARIAT}

1. Umur Ayah dan Ibu

Hasil penelitian 69 responden terdapat umur Ayah dan Ibu mayoritas $\geq 30$ sebanyak 53 orang $(76.8 \%)$ dan 42 orang $(60.9 \%)$.

2. Pendidikan Ayah dan Ibu

Hasil penelitian 69 responden pendidikan Ayah dan Ibu mayoritas SD yaitu 28 orang $(40.6 \%)$ dan 21 orang (30.4\%).

3. Pekerjaan Ayah dan Ibu

Hasil penelitian 69 responden pekerjaan Ayah mayoritas nelayan yaitu 33 orang ( 47,8\%) dan pekerjaan Ibu mayoritas ibu rumah tangga sebanyak 56 orang $(81.2 \%)$.

4. Peran Orang Tua Dalam Pemberian Imunisasi Dasar Lengkap

Hasil penelitian 69 responden peran ayah dan ibu mayoritas Kurang Baik yaitu 38 orang $(55.1 \%)$ dan 43 orang $(62,3 \%)$.

5. Keterjangkauan Tempat Pelayanan Kesehatan Dalam Pemberian Imunisasi Dasar Lengkap

Hasil penelitian 69 responden diperoleh keterjangkauan tempat pelayanan kesehatan mayoritas tempat pelayanan yang terjangkau $\leq 500 \mathrm{M} 38$ orang $(55,1 \%)$ dan tempat pelayanan tidak terjangkau > $500 \mathrm{M}$ yaitu 31 orang (44.9\%). 
6. Status Imunisasi Dasar Lengkap

Hasil dari penelitan 69 responden diperoleh bahwa bayi yang mendapatkan imunisasi lengkap sebanyak 33 orang $(47,8 \%)$ sedangkan yang tidak mendapatkan imunisasi lengkap sebnayak 36 orang $(52,2 \%)$.

\section{HASIL ANALISIS BIVARIAT}

\section{Peran Orang Tua}

a. Peran Ayah

Tabel 4.7

Hubungan Peran Ayah Dalam Pemberian Imunisasi Dasar Lengkap

\begin{tabular}{|c|c|c|c|c|c|c|c|}
\hline \multirow{3}{*}{ Peran Ayah } & \multicolumn{4}{|c|}{$\begin{array}{c}\text { Status } \\
\text { Kelengkapan Imunisasi }\end{array}$} & \multirow{2}{*}{\multicolumn{2}{|c|}{ Total }} & \multirow{3}{*}{$P$ Value } \\
\hline & \multicolumn{2}{|c|}{ Tidak Lengkap } & \multicolumn{2}{|c|}{ Lengkap } & & & \\
\hline & $\mathbf{n}$ & $\%$ & $\mathbf{n}$ & $\%$ & $\mathbf{n}$ & $\%$ & \\
\hline Kurang Baik & 25 & 65.8 & 13 & 34.2 & 38 & 100 & \multirow{3}{*}{0.024} \\
\hline Baik & 11 & 35.5 & 20 & 64.5 & 31 & 100 & \\
\hline $\mathrm{N}$ & 36 & 52.2 & 33 & 47.8 & 69 & 100 & \\
\hline
\end{tabular}

Berdasarkan tabel 4.7 diketahui dari 69 Hasil uji statistik dengan menggunakan uji responden didapatkan bahwa peran ayah Chi Square dengan $\alpha=0.05$ diperoleh nilai termasuk dalam kategori peran kurang baik $P$ value $=0.024$, sehingga $\mathrm{H}_{0}$ ditolak berarti dengan pemberian imunisasi dasar tidak dapat dikatakan bahwa terdapat hubungan lengkap yaitu sebanyak 25 orang $(65.8 \%)$ antara peran ayah dalam pemberian dan pemberian imunisasi dasar lengkap imunisasi dasar lengkap di wilayah kerja yaitu 13 orang (34.2\%), sedangkan kategori puskesmas daik kabupaten lingga tahun peran baik dengan pemberian imunisasi 2020.Penelitian ini sejalan dengan penelitian tidak lengkap yaitu 11 orang $(35.5 \%)$ dan F. Ningsih, E. Kasanova, and I. Devitasari pemberian imunisasi dasar lengkap (2016) yaitu mayoritas ayah termasuk dalam sebanyak 20 orang $(64.5 \%)$. kategori peran kurang baik sebanyak 26 
orang $(55.3 \%)$ dari 47 responden. Peran ayah mempunyai tanggung jawab sebagai kepala keluarga yang sangat dominan dalam pengambilan keputusan dikeluarga. Tidak jarang bayi tidak mendapatkan imunisasi dikarenakan tidak diperboleh oleh ayahsuami untuk mendapatkan imunisasi, sehingga ibu mematuhi perintah suaminya tidak mengikutsertakan bayinya untuk imunisasi. Peran ayah sangat dibutuhkan oleh keluarga untuk mengambil keputusan salah satu nya untuk mendapatkan imunisasi pada bayinya.

\section{b. Peran Ibu}

Tabel 4.8

Hubungan Peran Ibu Dalam Pemberian Imunisasi Dengan Status Imunisasi Dasar Lengkap Bayi

\begin{tabular}{|c|c|c|c|c|c|c|c|}
\hline \multirow{2}{*}{ Peran Ibu } & \multicolumn{3}{|c|}{ Status Kelengkapan Imunisasi } & \multicolumn{2}{c|}{ Total } & \multirow{2}{*}{ P Value } \\
\cline { 2 - 7 } & \multicolumn{2}{|c|}{ Tidak Lengkap } & \multicolumn{2}{|c|}{ Lengkap } & \multicolumn{2}{c|}{} \\
\cline { 2 - 7 } & $\mathbf{n}$ & $\%$ & $\mathbf{n}$ & $\%$ & $\mathbf{n}$ & $\%$ & \\
\hline Kurang Baik & 27 & 62.8 & 16 & 37.2 & 43 & 100 & \multirow{2}{*}{0.043} \\
\hline Baik & 9 & 34.6 & 17 & 65.4 & 26 & 100 & \\
\hline N & 36 & 52.2 & 33 & 47.8 & 69 & 100 & \\
\hline
\end{tabular}

Berdasarkan tabel 4.8 diketahui dari 69 responden yang ibu termasuk dalam kategori peran kurang baik dengan pemberian imunisasi dasar tidak lengkap yaitu sebanyak 27 orang (62.8\%) dan pemberian imunisasi dasar lengkap yaitu 16 orang (37.2\%), sedangkan kategori peran baik dengan pemberian imunisasi tidak lengkap yaitu 9 orang $(34.6 \%)$ dan pemberian imunisasi dasar lengkap sebanyak 17 orang $(65.4 \%)$.

Hasil uji statistik dengan menggunakan uji Chi Square dengan $\alpha=0.05$ diperoleh nilai $P$ value $=0.043$, sehingga $\mathrm{H}_{0}$ ditolak berarti 
dapat dikatakan bahwa terdapat hubungan antara peran ibu dalam pemberian imunisasi dasar lengkap di wilayah kerja puskesmas daik kabupaten lingga tahun 2020. Hasil penelitian I. Devitasari (2016) menunjukan bahwa kekhawatiran ibu mengenai injeksi menyebabkan ibu enggan memberikan imunisasi dasar, dari penelitian ini ibu yang termasuk peran buruk mengatakan bahwa merasa cemas dan tegang setiap kali bayi hendak imunisasi. Peran ibu sangat berpengaruh terhadap pemberian imunisasi karena sebagian besar menghabiskan waktu nya mengurusi pekerjaan rumah tangga terutama dalam memperhatikan kesehatan keluarga salah satunya membawa bayi untuk mendapatkan imunisasi dasar lengkap.

\section{Keterjangkauan Tempat Pelayanan}

\section{Kesehatan}

Tabel 4.9

Hubungan Keterjangkauan Tempat Pelayanan Kesehatan Dalam Pemberian Imunisasi Dasar Lengkap

\begin{tabular}{|c|c|c|c|c|c|c|c|}
\hline \multirow{2}{*}{$\begin{array}{c}\text { Keterjangkauan } \\
\text { Tempat Pelayanan }\end{array}$} & \multicolumn{2}{|c|}{ Status Kelengkapan Imunisasi } & \multicolumn{2}{|c|}{ Total } & \multirow{2}{*}{ P Value } \\
\cline { 2 - 7 } & \multicolumn{2}{|c|}{ Tidak Lengkap } & \multicolumn{2}{|c|}{ Lengkap } & \multicolumn{2}{|c|}{} \\
\cline { 2 - 7 } & $\mathbf{n}$ & $\%$ & $\mathbf{n}$ & $\%$ & $\mathbf{n}$ & $\%$ & \\
\hline $\begin{array}{c}\text { Tidak Terjangkau > } \\
500 \mathrm{M}\end{array}$ & 9 & 29.0 & 22 & 71.0 & 31 & 100 & \\
\hline Terjangkau $\leq 500 \mathrm{M}$ & 27 & 71.1 & 11 & 28.9 & 38 & 100 & \multirow{2}{*}{0.001} \\
\hline $\mathrm{N}$ & 36 & 52.2 & 33 & 47.8 & 69 & 100 & \\
\hline
\end{tabular}


Berdasarkan tabel 4.9 diketahui dari 69 responden didapatkan bahwa diperoleh keterjangkauan tempat pelayanan kesehatan kategori tidak terjangkau > 500 M dengan pemberian imunisasi yang tidak lengkap yaitu sebanyak 9 orang (29.0\%) dan pemberian imunisasi lengkap yaitu 22 orang (71.0\%), sedangkan kategori tempat pelayanan kesehatan yang terjangkau $\leq 500$ $M$ dengan pemberian imunisasi tidak lengkap yaitu 27 orang $(71.1 \%)$ dan pemberian imunisasi lengkap sebanyak 11 orang (28.9\%). Hasil uji statistik dengan menggunakan uji Chi Square dengan $\alpha=$ 0.05 diperoleh nilai $P$ value $=0.001$, sehingga $\mathrm{H}_{0}$ ditolak berarti dapat dikatakan bahwa terdapat hubungan yang bermakna antara keterjangkauan tempat pelayanan kesehatan dalam pemberian imunisasi dasar lengkap di wilayah kerja puskesmas daik kabupaten lingga tahun 2020. Penelitian ini sejalan dengan penelitian Elly Istriyati (2011) bahwa responden yang keterjangkauan ke tempat pelayanan imunisasi dekat sebanyak 42 orang (70\%) sedangkan keterjangkauan tempat pelayanan jauh sebnayak 18 orang (30\%). Menurut peneliti bahwa tempat pelayanan kesehatan yang jaraknya jauh membuat orang untuk enggan mendatanginya, karena selain biaya pelayanan ada biaya tambahan yaitu biaya transportasi. Bagi orang-orang yang berfikir sederhana dan ekonomi kurang mungkin akan memutuskan tidak datang ke sarana pelayanan. Hal ini disebabkan keterjangkauan sarana pelayanan kesehatan oleh masyarakat.

\section{KESIMPULAN}

1. Ada hubungan antara peran ayah dalam pemberian imunisasi dasar lengkap di wilayah kerja puskesmas daik kabupaten lingga tahun 2020 ( $p$ value $=$ $0.024)$.

2. Ada hubungan antara peran ibu dalam pemberian imunisasi dasar lengkap di wilayah kerja puskesmas daik kabupaten lingga tahun 2020 ( $p$ value $=$ $0.043)$.

3. Ada hubungan antara keterjangkauan tempat pelayanan dalam pemberian imunisasi dasar lengkap di wilayah kerja puskesmas daik kabupaten lingga tahun 2020 ( $p$ value $=0.001)$.

4. Dapat disimpulkan terdapat hubungan peran orang tua dan keterjangkauan tempat pelayanan kesehatan dalam pemberian imunisasi dasar lengkap di Wilayah Kerja Puskesmas Daik Kabupaten Lingga Tahun 2020. 


\section{DAFTAR PUSTAKA}

Aris, Rizqiawan, 2008. Faktor yang Mempengaruhi Ibu dalam Ketidakikutsertaan Balitanya ke Pekan Imunisasi Nasional (PIN) Polio di Wilayah Kerja Puskesmas Mulyorejo Surabaya. Skripsi. Universitas Airlangga Surabaya

Badan Pusat Statistik. Statistik lingkungan hidup di Indonesia. diunduh tanggal 10

Oktober2013.Diaksesdi:http://www .bps.go.id/hasil_publikasi/stat_lh_2 013/files/search/searchtext.xml,

Depkes 2010. Kemenkes Targetkan Tahun 2014 Seluruh Desal Kelurahan $100 \%$ UCI. http://depkes.go.id/index.php/comp onent/content/article/43newsslider/1106-kemenkestargetkan-tahun-2014-seluruhdesakelurahan-100-uci.html. 2019.10.12

Devitasari,2016. "Hubungan Peran Orang Tua Dan Petugas Kesehatan Dengan Kelengkapan Imunisasi Pada Keluarga Yang Memiliki Bayi Usia 0-12 Bulan Di Wilayah Kerja Puskesmas Pahandut Kota Palangka Raya," J. SURYA, 2016.

Dinas Kesehatan Kab. Kebumen 2012.

Sekilas Tentang Penyakit Yang Dapat Dicegah Dengann Imunisasi (PD3I) Yang Menjadi Program
Pemerintah.

http://dinkeskebumen.wordpress.co $\mathrm{m} / 2012 / 11 / 09 /$ sekilas-tentangpenyakit-yang-dapat-dicegahdengan-imunisasi-pd3i-yangmenjadi-program-pemerintah/. 2019.10.12

Elly Istriyati ， $6450406507 \quad$ (2011) FAKTOR-FAKTOR YANG BERHUBUNGAN DENGAN KELENGKAPAN IMUNISASI DASAR PADA BAYI DI DESA KUMPULREJO KECAMATAN ARGOMULYO KOTA SALATIGA. Under Graduates thesis, Universitas Negeri Semarang.

http://repository.uinjkt.ac.id/dspace /bitstream/123456789/33020/1/NU RHIDAYATI-FKIK.pdf http://www.who.int/topics/immuni zation/en/. [14 November 2016]. https://www.mendeley.com/catalog ue/hubungan-peran-orang-tua-danpetugas-kesehatan-dengankelengkapan-imunisasi-padakeluarga-yang-memil/.2019.10.13 https://www.mendeley.com/catalog ue/hubungan-peran-suami-dengankepatuhan-ibu-dalammelaksanakan-imunisasi-dasarlengkap-pada-balita-di/.2019.10.12 https://www.researchgate.net/publi cation/327699738_PERILAKU_IB 
U_DALAM_IMUNISASI_DASA

R_LENGKAP_DI_PUSKESMAS

GAYAM_KABUPATEN_SUMEN EP

Isnayni, E. 2016. Hubungan Karakteristik Ibu dan Peran Keluarga (Inti dan Non-Inti) dengan Kelengkapan Imunisasi Dasar pada Bayi di Puskesmas Pucuk Kabupaten Lamongan. Skripsi.Surabaya: Universitas Airlangga.

Kementerian Kesehatan Republik Indonesia 2016.Pertanyaan Populer Tentang Imunisasi. Jakarta : Percetakan Negara.

Mathilda albertina, sari febriana. sari pediatri, november 2016, Kelengkapan ImunisasiDasar Anak Balita dan Faktor yang Berhubungan di Poliklinik Anak di Jakarta, Sari Pediatri,vol. 11, juni, p. 1.

Methilda.M. Kelengkapan Imunisasi Dasar Anak Balita Dan Faktor-Faktor Yang Berhubungan Di Poliklinik Anak Beberapa Rumah Sakit Di Jakarta Dan Sekitarnya Pada Bulan $\quad$ Maret 2008. http://lontar.ui.ac.id/file?file=digital /125308S5678Hubungan\%20karakt eristik-Analisis.pdf. 2019.10.13

Miftahol Hudhah,Atik Choirul Hidajah. Perilaku Ibu Dalam Imunisasi Dasar Lengkap di Puskesmas
Gayam Kabupaten Semenep.Jurnal Promkes

Mulyanti, Y. 2013. Faktor-faktor internal yang berhubungan dengan pemberian imunisasi dasar balita usia 1-5 tahun di wilayah kerja Puskesmas Situgintung Tahun 2013. [skripsi]. Fakultas Kedokteran Dan Ilmu Kesehatan : Universitas Islam Negri Syarif Hidayatullah.

N. Millatun, M. Susi, and Khodijah, "Hubungan peran suami dengan kepatuhan ibu dalam melaksanakan imunisasi dasar lengkap pada balita di kelurahan kalinyamat kulon kota tega," kesehatan, 2018.

Nina Siti Mulyani,SST dan Mega Rinawati.2013. Imunisasi Untuk Anak.Yogyakarta Nuha Medika.

Ningrum, E.P. Faktor-Faktor Yang Mempengaruhi Kelengkapan Imunisasi Dasar Pada Bayi Di Puskesmas Banyodono Kabupaten Boyolali.

http://publikasiilmiah.ums.ac.id/bits team/handle/123456789/460/1b.pdf ?sequence $=1.2019 .10 .15$

Nurhidayati.2016.Hubungan Pengetahuan Ibu Tentang Imunisasi Dasar Terhadap Kelengkapan Imunisasi Dasar Di Wilayah Kerja Puskesmas Pisangan Kota Tenggerang Selatan Tahun 
2016.Skripsi

Perpustakaan

Universitas Airlangga.

Pratiwi, L.N. 2012. Faktor-faktor yang berhubungan dengan pemberian imunisasi dasar balita umur 12-23 bulan di Indonesia tahun 2010. [skripsi]. Fakultas Kesehatan Masyarakat : Universitas Indonesia. Prayoga,A.2009. Kelengkapan Imunisasi Dasar Pada Anak Usia 1 -5 tahun. http://saripediatri.idai.or.id/pdfile/1 1-1-3.pdf. 2019.10.15

Santi.J.D.K.,2016.

Upaya

Peningkatan

Layanan

Imunisasi Dalam Pencapaian UCI denga Metode Quality Function Deployment (QDF) di Kota Surabaya. Fakultas Kesehatan Masyarakat Universitas Airlangga. Available at

www.repository.unair.ac.id

Setyowati, N.P. Rasni, H. Dewi, E.I. 2013. HubunganPeran Ayah di Keluarga dengan Keikutsertaan Balita Usia 2-24 dalam Pelaksanaan Imunisasi DPT di Desa Pace Kecamatan Silo Kabupaten Jember, Artikel ilmiah hasil penelitian mahasiswa UNEJ.

Vivi,Triana. (2016). Faktor Yang Berhubungan dengan Pemberian Imunisasi Dasar Lengkap pada
Bayi Tahun 2015. Jurnal KesehatanMasyarakat Andalas, 10No.2,123_135.Retrievedfromhttp ://jurnal.fkm.unand.ac.id/index.php/ jkma/article/view/196. 2019.10.15

WHO, 2014. Immunization. WHO. tersedia di :

Widayati,Sri.2009. Hubungan Tingkat Pengetahuan Ibu Tentang Imunisasi Polio Dengan Status Kelengkapan Imunisasi Polio Di Wilayah Kerja Puskesmas Tanon I Sragen. $\quad$ http://jurnal.stikesaisyiyah.ac.id/. 2019.10.15

Winarsih, S. Imavike, F. Yunita, R. 2013. Hubungan Peran Orang Tua dalam Pemberian Imunisasi Dasar dengan Status Imunisasi Bayi di Wilayah Kerja Puskesmas Dringu Kabupaten Probolinggo,Jurnal ilmu keperawatan, Vol. 1, Nopember,pp. 135-140

Yuliana Makamban , Ummu Salmah, Rahma 2014. Faktor yang Berhubungan dengan Cakupan Imunisasi Dasar Lengkap pada Bayi di Wilayah Kerja Puskesmas antara Kota Makassar. 